\title{
North American Blastomycosis
}

National Cancer Institute

\section{Source}

National Cancer Institute. North American Blastomycosis. NCI Thesaurus. Code C34429.

A pulmonary disease resulting from infection with Blastomyces dermatitidis, which is prevalent in North America. 